\title{
Activities and plans of the GGOS Focus Area Unified Height System
}

\author{
Laura Sanchez ${ }^{1}$ and Riccardo Barzaghi \\ ${ }^{1}$ Lead of the GGOS Focus Area Unified Height System, Deutsches Geodätisches Forschungsinstitut, Technische Universität \\ München (DGFI-TUM), Munich, Germany (Im.sanchez@tum.de) \\ ${ }^{2}$ Chair of the International Gravity Field Service, Department of Civil and Environmental Engineering, Politecnico di Milano, \\ Milano, Italy (riccardo.barzaghi@polimi.it)
}

The first three pages of this contribution present a summary of the main achievements and planned activities of the GGOS Focus Area Unified Height System as of May 2020. The following pages provide detailed information about each topic mentioned in the summary.

\section{Introduction (see Section $\underline{1}$ )}

The GGOS Focus Area Unified Height System (GGOS-FA-UHS, formerly Theme 1) was established during the GGOS Planning Meeting 2010 (February 1 - 3, Miami/Florida, USA) to continue the activities initiated by the IAG ICP1.2: Vertical Reference Systems, 2003-2011 (Ihde et al., 2007).

Objective: Unification of the existing height systems through the definition and realisation of a global vertical reference system that

- supports geometrical (ellipsoidal) and physical (normal, orthometric, geoid) heights worldwide with centimetre precision in a global frame;

- enables the unification of all existing physical height systems (i.e., all geopotential differences shall be referred to one and the same reference equipotential surface with potential $\left.W_{0}\right)$; and

- provides high-accuracy and long-term stability of the vertical coordinates.

Goals of the GGOS FA-UHS (as in Geodesist's Handbook 2012, 2016, see Section 1)

Short-term goals:

- To establish a global vertical reference level and its potential value $W_{0}$.

- Refinement of standards and conventions for the definition and realisation of a world physical height system.

Mid-term goals:

- To develop GGOS products for the realisation of a world physical height system: reference frame, global height system unification, registry and metadata of existing height systems.

\section{Long-term goals:}

- To maintain and use in practice the world height system: temporal changes, update of definition and realisation according to new geodetic developments, servicing the vertical datum needs to other geosciences.

\section{GGOS FA-UHS: activities 2011 - 2015}

- Determination of a conventional global reference level $W_{0}$ based on the newest geodetic models and including reliability assessment (Sánchez et al., 2017) (see Sections $\underline{4}$ and $\underline{5}$ ): 
Sánchez L, Barzaghi R (2020). Activities and plans of the GGOS Focus Area Unified Height System. EGU General Assembly 2020, EGU2020-8625, https://doi.org/10.5194/egusphere-egu2020-8625.

- Advances regarding standards and conventions for the definition and realisation of a world height system:

- Recommendations of the IAG Ad-hoc group on an International Height Reference System - IHRS (Ihde et al., 2015; 2017; see Section $\underline{3}$ )

- BPS Inventory of Standards and Conventions used for the IAG Products (Angermann et al. 2016, see Section 2).

$\rightarrow$ Important outcome: IAG Resolution No. 1, 2015: Definition and Realisation of an International Height Reference System (IHRS), see Annex A.

\title{
GGOS FA-UHS: activities 2015 - 2019
}

Objective: To investigate appropriate strategies for the realisation of the IHRS. Four main topics were considered:

(1) Establishment of a global reference network for the IHRS realisation: the International Height Reference Frame (IHRF). A preliminary reference network for the IHRF was completed in Apr 2019 (see Section $\underline{6}$ ):

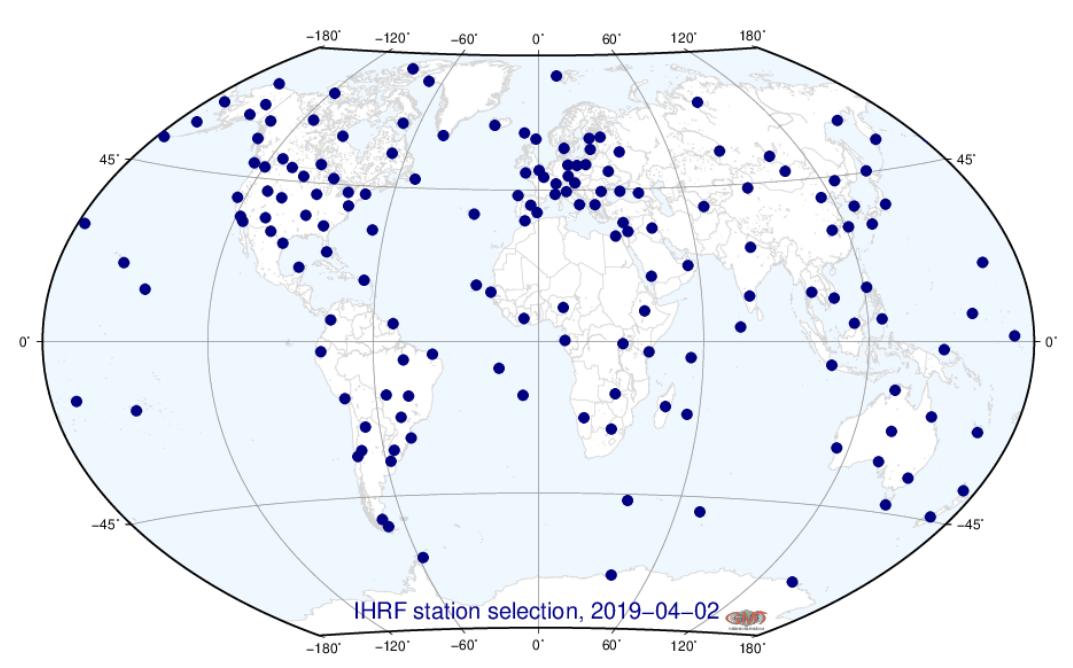

\author{
Preliminary reference \\ network for the IHRF: \\ 170 stations well- \\ distributed world- \\ wide, materialized by \\ GNSS continuously \\ operating stations and \\ co-located with VLBI \\ (30 sites), SLR (40 \\ sites), DORIS (35 sites), \\ absolute gravity - IGRF \\ (77 sites), tide gauges \\ (26 sites), and national \\ levelling networks (23 \\ sites).
}

(2) Evaluation of different strategies for the determination of potential values as IHRS/IHRF reference coordinates (main action the Colorado experiment), see Section $\underline{7}$.

(3) Identification of required standards, conventions and procedures needed to ensure consistency between the definition (IHRS) and the realisation (IHRF), see Section $\underline{7}$.

(4) Strategy for the integration (transformation) of existing vertical datums into the IHRS/IHRF (Sánchez and Sideris, 2017), see Section $\underline{8}$.

\section{Determination of potential values as IHRS/IHRF coordinates: The Colorado experiment (see Section $\underline{7}$ )}

Objective: To compute geoid, quasi-geoid and potential values using the same input data and the own methodologies (software) of colleagues involved in the gravity field modelling. To minimise discrepancies and to obtain as similar and compatible results as possible, a set of basic standards was released (Sánchez et al., 2018a). This action was conducted by

- GGOS JWG: Strategy for the realisation of the IHRS (chair: L Sánchez) 
Sánchez L, Barzaghi R (2020). Activities and plans of the GGOS Focus Area Unified Height System. EGU General Assembly 2020, EGU2020-8625, https://doi.org/10.5194/egusphere-egu2020-8625.

(C) Author(s) 2020.

(0) This work is distributed under the Creative Commons Attribution 4.0 License.

- $\quad$ IAG JWG 2.2.2: The $1 \mathrm{~cm}$ geoid experiment (chair: YM Wang)

- IAG SC 2.2: Methodology for geoid and physical height systems (chair: J Ågren)

- ICCT JSG 0.15: Regional geoid/quasi-geoid modelling - Theoretical framework for the subcentimetre accuracy (chair: J Huang)

The Colorado experiment started at the IAG/IASPEI Scientific Assembly (Aug 2017, Kobe). First results were discussed at the GGHS2018 Symposium (Sep 2018, Copenhagen). A second computation was ready for the EGU2019 (Apr 2019, Vienna) and some refinements (third computation) were delivered in Jun 2019. The results were extensively discussed at the IUGG2019, Symposium G02: Static Gravity Field and Height Systems (July 2019, Montreal), see Section 7. In addition, a Journal of Geodesy special issue on Reference Systems in Physical Geodesy is in preparation. This special issue will include key contributions for the establishment of the IHRS/IHRF and the IGRS/IGRF (International Gravity Reference System and Frame) as well as the scientific description of the individual solutions contributing to the Colorado experiment.

$\rightarrow$ Important output: IAG Resolution No. 3, 2019: Establishment of the International Height Reference Frame (IHRF), see Annex B.

GGOS FA-UHS: planned activities 2019 - 2023, see Section $\underline{9}$.

(1) Based on the Colorado experiment outcomes, to elaborate a document with detailed standards and conventions for the realisation and maintenance of the IHRS.

(2) With the support of the IAG Commission 2, the IGFS and the ICCT to promote the study of

- quality assessment in the determination of potential values;

- determination of potential changes with time $\dot{W}$;

- realisation of the IHRS in marine areas.

With this purpose, following working/study groups are established for the term 2019-2023:

- IAG Commission 2 working group Error assessment of the 1-cm geoid experiment, chaired by M Willberg (Germany) and T Jiang (China).

- IAG ICCT study group Geoid/quasi-geoid modelling for realisation of the geopotential height datum, chaired by J Huang (Canada).

- GGOS-FA-UHS and IGFS working group Implementation of the International Height Reference Frame (IHRF), chaired by L Sánchez (Germany) and R Barzaghi (Italy).

(3) In agreement with the IGFS and the IAG Commission 2, to design a strategy to install an operational infrastructure within the IGFS to ensure the maintenance and availability of the IHRF in a long-term basis. Aspects to be considered are:

- Updates of the IHRS definition and realisation according to future improvements in geodetic theory and observations.

- Regular updates of the IHRF (e.g. IHRFyyyy) according to new stations, coordinate changes with time, improvements in the estimation of reference coordinates and modelling of the Earth's gravity field, etc.

- Support in the realisation and utilisation of the IHRS/IHRF at regional and national level.

- To guarantee an organisational and operational infrastructure to ensure the sustainability of the IHRF. 


\title{
Activities and plans of the GGOS Focus Area Unified Height System
}

\author{
Laura Sanchez ${ }^{1}$ and Riccardo Barzaghi ${ }^{2}$ \\ ${ }^{1}$ Lead of the GGOS Focus Area Unified Height System, Deutsches Geodätisches Forschungsinstitut, Technische Universität \\ München (DGFI-TUM), Munich, Germany (Im.sanchez@tum.de) \\ ${ }^{2}$ Chair of the International Gravity Field Service, Department of Civil and Environmental Engineering, Politecnico di Milano, \\ Milano, Italy (riccardo.barzaghi@polimi.it)
}

\begin{abstract}
The Global Geodetic Observing System (GGOS) of the International Association of Geodesy (IAG), providing precise geodetic infrastructure and expertise for monitoring the System Earth, promotes the standardisation of height systems worldwide. The GGOS Focus Area Unified Height System (GGOS-FAUHS, formerly Theme 1) was established at the 2010 GGOS Planning Meeting (February 1 - 3, Miami, Florida, USA) to lead and coordinate these efforts. Starting point was the results delivered by the IAG Inter-Commission Project 1.2 Vertical Reference Frames (IAG-ICP1.2-VRF), which was operative from 2003 to 2011. During the 2011-2015 term, different discussions focussed on the best possible definition of a global unified vertical reference system resulted in the IAG resolution for the Definition and realisation of an International Height Reference System (IHRS) that was approved during the 2015 General Assembly of the International Union of Geodesy and Geophysics (IUGG) in Prague, Czech Republic. In the term 2015-2019, actions dedicated to investigate the best strategy for the realisation of the IHRS (i.e., the establishment of the International Height Reference Frame - IHRF) were undertaken. In particular, a preliminary station selection for the IHRF reference network was achieved and different computation procedures for the determination of potential values as IHRS coordinates were evaluated. For the present term, 2019-2023, the objectives of the GGOS-FA-UHS are $(i)$ to compile detailed standards, conventions, and guidelines to support a consistent determination of the IHRF at global, regional and national levels; (ii) to coordinate with regional/national experts in gravity field modelling the computation of a first IHRF solution; and (iii) to design an operational infrastructure that ensures the long-term sustainability and reliability of the IHRS/IHRF. This infrastructure should operate under the responsibility of the International Gravity Field Service (IGFS). The present contribution summarises the main achievements of the GGOS-FA-UHS and provides a review of the open questions that need to be resolved in the near future.
\end{abstract}

\section{Introduction}

Most of the existing physical height systems do not fulfil the accuracy requirements of modern Geodesy. They refer to local sea surface levels, are stationary (do not consider variations in time), realise different physical height types (orthometric, normal, normal-orthometric heights, etc.), and their combination in a global frame presents uncertainties at the metre level. The International Association of Geodesy (IAG), as the organisation responsible for the advancement of the science of Geodesy, enhances the definition and realisation of geodetic reference systems that are in accordance with the increased precision of modern observational techniques and are capable of supporting the 
Sánchez L, Barzaghi R (2020). Activities and plans of the GGOS Focus Area Unified Height System. EGU General Assembly 2020, EGU2020-8625, https://doi.org/10.5194/egusphere-egu2020-8625.

(C) Author(s) 2020.

(1) This work is distributed under the Creative Commons Attribution 4.0 License.

present needs of science and society regarding geo-referenced data of high resolution (IAG, 2017). During the last decades, a huge progress in the realisation of the International Celestial Reference System (ICRS, Ma and Feissel, 1997) and the International Terrestrial Reference System (ITRS, Petit and Luzum, 2010) has been achieved. The definition, realisation, and maintenance of these two systems guarantee a globally unified geometric reference frame with reliability at the $\mathrm{cm}$-level. An equivalent high-precise global physical reference system is missing. There is no doubt that the existing height systems follow the best conditions offered by the state-of-the-art at the time when they were established. However, their realisation was implemented individually, applying in general nonstandardised procedures. As a consequence, at present there are some hundred local and regional physical height systems in use, and they exhibit discrepancies with respect to each other up to $\pm 2 \mathrm{~m}$. The geodetic data depending on them (e.g. physical heights, gravity anomalies, geoid models, digital terrain models, etc.) are usable in limited geographical areas only; their global combination or with satellite-based data (especially Global Navigation Satellite Systems' (GNSS) positioning) shows discrepancies with magnitudes very much higher than the accuracy required today.

In this framework, a current main objective of the IAG is the implementation of an integrated Global Geodetic Reference System (GGRS) that simultaneously supports the consistent determination and monitoring of the Earth's geometry, rotation, and gravity field changes with high accuracy worldwide (IAG, 2017). This objective is in accordance with the resolution adopted by the United Nations General Assembly on a Global Geodetic Reference Frame (GGRF) for Sustainable Development (A/RES/69/266) on February 26,2015 . The establishment of an integrated global geodetic reference system necessarily implies the implementation of a worldwide-unified (standardised) physical reference system. In this regard, the main objectives are:

- To provide a reliable frame for consistent analysis and modelling of global phenomena and processes affecting the Earth's gravity field (e.g. redistribution of masses in the atmosphere, oceans, continents and the Earth's interior) and the Earth's surface geometry (e.g. deformations), and

- To support a precise combination of physical and geometric heights in order to exploit at a maximum the advantages of satellite geodesy (e.g. combination of GNSS with gravity field models for worldwide unified precise height determination).

With the purpose to bring together existing initiatives towards the establishment of a global unified vertical reference system and to address the activities to be faced, the GGOS Focus Area Unified Height System (GGOS-FA-UHS, formerly GGOS Theme 1) was established during the GGOS Planning Meeting 2010 (February 1 - 3, Miami/Florida, USA). Starting point were the results delivered by the IAG InterCommission Project 1.2 Vertical Reference Frames (IAG-ICP1.2-VRF; Ihde, 2007), which are compiled in the document Conventions for the Definition and Realisation of a Conventional Vertical Reference System -CVRS- (Ihde et al., 2007). These CVRS describe the basic aspects to be taken into consideration for the definition and realisation of a global vertical reference system that fulfils the requirements mentioned above. Based on this document, the initial objectives of GGOS-FA-UHS were defined as (Sideris and Ihde, 2012; Sánchez, 2016a): 
Sánchez L, Barzaghi R (2020). Activities and plans of the GGOS Focus Area Unified Height System. EGU General Assembly 2020, EGU2020-8625, https://doi.org/10.5194/egusphere-egu2020-8625.

(C) Author(s) 2020.

(c) This work is distributed under the Creative Commons Attribution 4.0 License.

- To refine standards and conventions for the definition and realisation of a global unified vertical reference system, including unification/harmonisation of standards and conventions that are used by the geometric and gravity Scientific Services of the IAG.

- To make a recommendation about the reference value $W_{0}$ to be adopted as the conventional reference level for the global vertical reference system. This $W_{0}$ value must also be promoted as a defining parameter for the computation of an updated mean Earth ellipsoid.

- To coordinate the generation of a set of consistent GGOS products for the realisation of the global vertical reference system, including:

- A proposal for a global vertical reference frame given by a set of worldwide homogenously distributed geodetic stations and the corresponding densifications at continental and national levels.

- Compilation of guidelines for height system unification containing a detailed description about the required input data, analysis strategy, and expected products.

- Implementation of an information system containing an inventory of the existing local/regional height systems and their characteristics (e.g. locations of the reference tide gauges, period(s) used for computing the mean sea level introduced as a zeroheight, gravity reductions applied to levelling, precision of levelling and gravity data, etc.).

- Design of strategies for the appropriate maintenance and use in practice of the global vertical reference system considering determination of time-dependent changes of the vertical reference frame and alignment/update of the definition and realisation of the vertical reference system with future improvements in geodetic observations, data analysis, and modelling.

- Servicing the vertical datum needs of other geosciences such as, e.g., hydrography and oceanography.

In accordance with these objectives, in the following we summarise the achievements towards the establishment of a global unified vertical reference system.

\section{Inventory of standards presently used in the vertical coordinate determination}

GGOS, through its Bureau of Products and Standards (GGOS-BPS), started in 2012 the compilation of an inventory of standards, constants, resolutions, and conventions adopted and used by IAG and its components for the generation of IAG products (Angermann et al., 2016). Goals are to contrast adopted and applied standards and conventions; to identify gaps, inconsistencies and deficiencies; and to propose new standards if necessary. The first version of the GGOS-BPS inventory was published in 2016 (Angermann et al., 2016) and an updated version, including recent innovations in the geodetic data analysis and modelling, is being prepared to be published in 2020 in the IAG Geodesist's Handbook (see e.g. Angermann et al., 2018; 2019). The GGOS-FA-UHS supports this activity by compiling and maintaining up-to-date the chapter 4.6 Height systems and their realisations. This document describes in detail the discrepancies of the local physical height systems and their combination with geometric (ellipsoidal) heights and (quasi-)geoid models. In the 2016 version of the inventory, special care was given to set down a detailed list of corrections or reductions applied to the different vertical coordinates to remove or retain geophysical effects influencing the vertical positioning. In the updated 
Sánchez L, Barzaghi R (2020). Activities and plans of the GGOS Focus Area Unified Height System. EGU General Assembly 2020, EGU2020-8625, https://doi.org/10.5194/egusphere-egu2020-8625.

(C) Author(s) 2020.

(a) This work is distributed under the Creative Commons Attribution 4.0 License.

2020 version, we included a description of the standards that are being discussed for the implementation of a global unified height system (see below).

\section{Conventions for the definition of a global vertical reference system}

In 2014, an ad-hoc group was established with the objective to outline the minimal requirements for the definition and realisation of a global unified physical vertical reference system (Ihde et al., 2015). This ad-hoc group was supported by the GGOS-FA-UHS (Sideris and Ihde, 2015), the GGOS Focus Area Understanding and Forecasting Sea-Level Rise and Variability (Schöne et al., 2015), the GGOS-BPS (Angermann et al., 2015), the GGOS working group Vertical Datum Standardisation (Sánchez, 2012; 2015), the International Gravity Field Service (IGFS; Forsberg et al., 2015); as well as the joint activities of IAG Commission 2 (Gravity Field) and the Consultative Committee for Mass and related quantities to agree about a strategy for metrology in absolute gravimetry (Marti et al., 2014).

The first recommendation of the ad-hoc group was to introduce a univocal name for the new system. During the last four decades, different names were used to identify a global vertical reference system, e.g. world height system, global vertical datum, world vertical datum, global vertical network, global height datum unification, global unification of height systems, global unified height reference system, etc. To avoid this multiple designation, the ad-hoc group recommended the name International Height Reference System (IHRS) with the realisation International Height Reference Frame (IHRF). This name is in agreement with the other reference systems and frames used in Geodesy: ICRS/ICRF, ITRS/ITRF, and IGRS/IGRF. The latter one refers to the International Gravity Reference System and Frame.

The ad-hoc group concentrated on discussing the basic requirements to establish a physical reference system, including a reference for the gravity field-depending heights (physical heights) and a reference for the gravimetry. The recommendations of this group were discussed during the 2015 General Assembly of the International Union of Geodesy and Geophysics (IUGG) in Prague, and they were presented and officially adopted by means of two IAG resolutions (Drewes et al., 2016): The first resolution is devoted to the definition and realisation of an International Height Reference System (see Annex A). The second resolution concentrates on the establishment of a Global Absolute Gravity Reference System.

The foundations for the definition and realisation of the IHRS are extensively discussed in Ihde et al. (2017). This publication is the scientific basis for the IAG Resolution No. 1, 2015 (Annex A) and provides the framework for the realisation of the IHRS. The fundamental conventions for the definition of the IHRS are:

- The vertical reference level is an equipotential surface of the Earth gravity field with the geopotential value $W_{0}=62636853.4 \mathrm{~m}^{2} \mathrm{~s}^{-2}$. $W_{0}$ is understood to be the potential of the geoid or the geoidal potential value.

- Parameters, observations, and data shall be related to the mean tidal system/mean crust.

- The unit of length is the meter and the unit of time is the second of the International System of Units (SI). 
Sánchez L, Barzaghi R (2020). Activities and plans of the GGOS Focus Area Unified Height System. EGU General Assembly 2020, EGU2020-8625, https://doi.org/10.5194/egusphere-egu2020-8625.

(C) Author(s) 2020.

(c) This work is distributed under the Creative Commons Attribution 4.0 License.

- The vertical coordinates (Fig. 1) are the differences $-\Delta W(P)$ between the potential $W(P)$ of the Earth's gravity field at the considered points $P$, and the geoidal potential value $W_{0}$; the potential difference $-\Delta W(P)$ is also designated as geopotential number $C(P)$ :

$$
C(P)=-\Delta W(P)=W_{0}-W(P)
$$

- The spatial reference of the position $P$ for the potential $W(P)=W\left(\mathbf{X}_{P}\right)$ is given by the coordinate vector $\mathbf{X}_{P}=\mathbf{X}(P)$ in the ITRS/ITRF.

The estimation of the coordinates $\mathbf{X}(P), W(P)$ (or $C(P))$ includes their variation with time, i.e., $d \mathbf{X}(P) / d t$, $d W(P) / d t$ (or $d C(P) / d t$ ). For practical purposes, positions $\mathbf{X}(P)$ may be transformed to ellipsoidal coordinates to get the geometric (or ellipsoidal) heights $h(P)$, and $C(P)$ may be transformed to a physical height (orthometric $H$, dynamic $H^{d}$ or normal height $H^{*}$ ). The determination of the potential values $W(P)$ and the transformation of geopotential numbers $C(P)$ to physical heights $H(P)$ require observables of the Earth's gravity field as a further element of the IHRS. Consequently, a consistent treatment of gravity, potential and physical heights is required. In other words: the definition and realisation of the ITRS (for the coordinates $\mathbf{X}(P)$ ), the IHRS (for the geopotential numbers $C(P)=W_{0}-W(P)$ ) and the IGRS (for the gravity values $g$ ) must be harmonised and consistent.
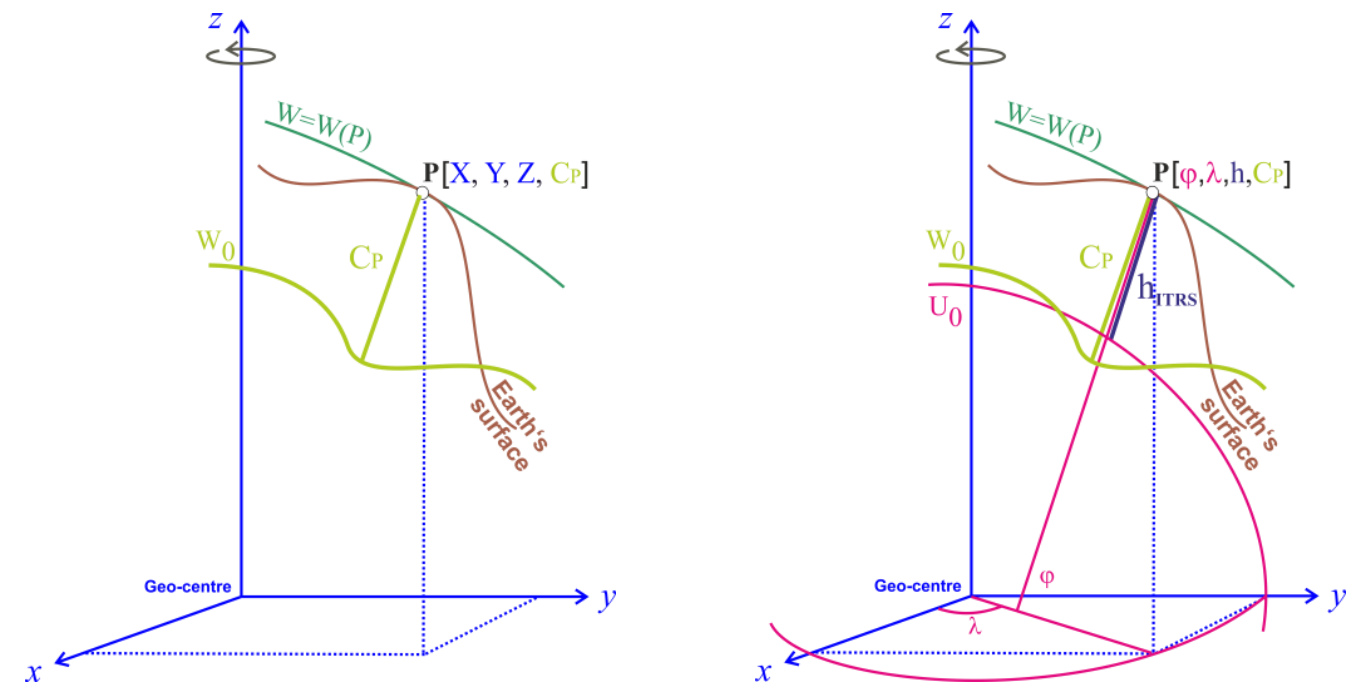

Fig 1. Coordinates of the International Height Reference System (IHRS): Station coordinates at the Earth's surface are given by the potential differences $C(P)=-\Delta W(P)$ and geocentric Cartesian coordinates $\mathbf{X}$ (left). For practical purposes, positions $\mathbf{X}$ may be transformed to ellipsoidal coordinates to get the geometric (or ellipsoidal) heights $h$ (right), and $\mathrm{C}(\mathrm{P})$ may be transformed to a physical height (orthometric $H$, dynamic $H^{d}$ or normal height $H^{*}$ ).

\section{Conventional reference value $W_{0}$}

$W_{0}$ is defined as the potential value of a particular level surface of the Earth's gravity field called the geoid. Since the most accepted definition of the geoid is understood to be the equipotential surface that coincides with the worldwide mean ocean surface, a usual empirical approximation to $W_{0}$ is the averaged potential value $W_{s}$ at the mean sea surface. In this way, $W_{0}$ depends not only on the Earth's gravity field modelling, but also on the mean sea surface modelling. Consequently, like any reference 
Sánchez L, Barzaghi R (2020). Activities and plans of the GGOS Focus Area Unified Height System. EGU General Assembly 2020, EGU2020-8625, https://doi.org/10.5194/egusphere-egu2020-8625.

(c) Author(s) 2020.

(1) This work is distributed under the Creative Commons Attribution 4.0 License.

parameter, $W_{0}$ should be based on adopted conventions that guarantee its uniqueness, reliability, and reproducibility; otherwise, there would be as many $W_{0}$ reference values as computations.

During the 2011 IUGG General Assembly, the GGOS-FA-UHS, the IAG Commissions 1 (Reference Frames) and 2 (Gravity Field) and the IGFS established a joint working group devoted to the Vertical Datum Standardisation (Sánchez, 2012; Sánchez et al., 2014). The main objective was to recommend a convention for the geopotential value $W_{0}$ to be introduced as the reference level for the realisation of the IHRS. At that time, the most used $W_{0}$ value was that included as a conventional constant in the conventions of the International Earth Rotation and Reference Systems' Service (IERS; Petit and Luzum 2010). This so-called IERS $W_{0}$ value corresponded to a best estimate available in 1998 (Burša et al., 1998; Groten 1999; 2004). It presents discrepancies of about $-2.6 \mathrm{~m}^{2} \mathrm{~s}^{-2}$ (corresponding to a level difference of around $+27 \mathrm{~cm}$ ) with respect to newest computations based on the latest Earth's surface and gravity field models (e.g. Čunderlík et al., 2009; 2014; Dayoub et al., 2012; Sánchez, 2008). In this context, the first activities faced by this working group concentrated on

- Making an inventory about the published $W_{0}$ computations to identify methodologies, conventions, standards, and models presently applied (cf. Sánchez, 2012) and

- Bringing together the different groups working on the determination of a global $W_{0}$ in order to coordinate these individual initiatives for a unified computation (cf. Sánchez et al. 2014).

The main objective of the unified computation was to perform a new $W_{0}$ estimation relying on the newest gravity field and sea surface models and applying standardised data and procedures. Following aspects were analysed:

- Sensitivity of the $W_{0}$ estimation to the Earth's gravity field model (especially omission and commission errors and time-dependent Earth's gravity field changes);

- Sensitivity of the $W_{0}$ estimation to the mean sea surface model (e.g., geographical coverage, time-dependent sea surface variations, accuracy of the mean sea surface heights);

- Dependence of the $W_{0}$ empirical estimation on the tide system; and

- Weighted computation of the $W_{0}$ value based on the input data quality.

According to this, different methodologies, different global gravity models, different mean sea surface models, different reference epochs, different weights for the input data, and different tide systems were evaluated for the $W_{0}$ computation. Based on the results, detailed conventions to ensure the reproducibility of a reference $W_{0}$ value were outlined. As the usual approximation of $W_{0}$ is the averaged potential value $W_{s}$ at the mean sea surface; it is expected that $W_{0}$ changes in the same way like $W_{s}$ changes. However, $W_{0}$ as a reference parameter should be defined as time-independent, and it should be necessary to decouple it from the Earth's gravity field and sea surface variations. Thus, it was recommended to adopt the potential value valid at a certain epoch and to keep it fixed for a longterm period (e.g., 20 years). If desired, it is possible to monitor the changes of the potential value $W_{S}$ at the sea surface and to compare it with the adopted $W_{0}$ value. When large differences appear (e.g., $> \pm 2 \mathrm{~m}^{2} \mathrm{~s}^{-2}$, equivalent to a mean sea level change of $\pm 20 \mathrm{~cm}$ ) the adopted $W_{0}$ may be replaced by an updated (best estimate) value. In conclusion, the working group members agreed to recommend the potential value obtained for the epoch $2010.0\left(62636853.4 \mathrm{~m}^{2} \mathrm{~s}^{-2}\right)$ as the present best estimate for 
Sánchez L, Barzaghi R (2020). Activities and plans of the GGOS Focus Area Unified Height System. EGU General Assembly 2020, EGU2020-8625, https://doi.org/10.5194/egusphere-egu2020-8625.

(C) Author(s) 2020.

(c) This work is distributed under the Creative Commons Attribution 4.0 License.

the $W_{0}$ value (Sánchez, 2015). IAG accepted this recommendation and adopted this value as the conventional reference level for the realisation of the IHRS, see IAG Resolution 1, 2015 (Annex A). A detailed description of the $W_{0}$ computation strategy, conventions, and results is given by Sánchez et al. (2016).

During the GGOS/IERS Unified Analysis Workshop held in Paris, France, July 10-12, 2017 (http://www.ggos.org/en/meetings/2017/unified-analysis-workshop/general/), the GGOS-BPS pointed out the necessity of consistency between the IERS Conventions and the IAG Resolution No. 1, 2015 and recommended the use of the IAG conventional $W_{0}$ value whenever a reference potential is needed in geodetic work. IERS followed this recommendation and in Nov 17, 2017, the old $W_{0}$ value from 1998 was replaced with the new one in the IERS Conventions (see IERS Convention 2010, version 1.1.0, available at http://iers-conventions.obspm.fr/conventions versions.php\#official target).

\section{IAG conventional $W_{0}$ value as defining parameter of a new mean Earth ellipsoid}

A mathematical model of the Earth is a fundamental tool for geodetic analysis and modelling. This kind of models relies on the theory of the level ellipsoid and they are usually defined in terms of the geocentric gravitational constant $(G M)$, the semi-major axis $(a)$, the dynamical form factor $\left(J_{2}\right)$, and the mean angular velocity of the Earth's rotation $(\omega)$. The semi-major axis $(a)$ may be replaced by the gravity potential at the ellipsoid surface $\left(U_{0}\right)$, which is assumed to be identical with the gravity potential at the geoid $\left(W_{0}\right)$. These models, called Geodetic Reference Systems (GRS) are based on the best parameter values available at specified epoch and are updated from time to time when new and more accurate observations and models are available. For instance, IUGG, IAG and the International Astronomical Union (IAU) agreed in 1979 upon the Geodetic Reference System 1980 (GRS80, Moritz 1980; 2000) as the replacement for the previous GRS67 (adopted at the 1967 IUGG General Assembly in Luzern). Since 1991, new values for some parameters have been introduced (e.g., GM and $a$ at the 1991 IUGG General Assembly in Vienna, $W_{0}$ at the 2015 IUGG General Assembly in Prague) but the replacement of GRS80 by an updated GRS has not been considered until now. This produces the use of different values for the same parameters in different applications. For instance, there are a wide variety of values for the semi-major axis $a$, which are mainly used in the computation of global gravity models. The (quasi-)geoid determination may be based on the GRS80 or on the ellipsoid WGS84 (World Geodetic System 1984; NIMA, 1997) introducing a discrepancy of about $90 \mathrm{~cm}$ in the obtained geoid undulations or height anomalies. An additional example is the use of the so-called TOPEX/Poseidon ellipsoid in the satellite altimetry data analysis, which differs from both the GRS80 and the WGS84 ellipsoids. This variety of values for the same ellipsoidal parameters causes inconsistencies and complicates the precise combination of geometric and physical geodetic products. Although, the geodetic community uses to deal with this kind of inconsistencies, it should keep in mind that geodetic products are utilised by other disciplines different to Geodesy and it is an unreasonable demand to request all these users to be familiarised with basic knowledge about geometrical and physical parameters of a reference ellipsoid and the transformation between different ones. In this way, even though the transformation from one ellipsoid to any other does not pose any theoretical problem, it is desired to introduce a conventional ellipsoid to be used in a common way for all geodetic (geometrical and physical) applications. 
Sánchez L, Barzaghi R (2020). Activities and plans of the GGOS Focus Area Unified Height System. EGU General Assembly 2020, EGU2020-8625, https://doi.org/10.5194/egusphere-egu2020-8625.

(C) Author(s) 2020.

(a) This work is distributed under the Creative Commons Attribution 4.0 License.

During the last four years, Oshchepkov $(2018,2019)$ studied in detail the available values for the ellipsoid parameters and advanced in the computation of an updated GRS using the current best estimates, including the IAG conventional $W_{0}$ value as a defining parameter instead of the usual semimajor axis $a$. Based on this work, the GGOS-BPS installed the working group Towards a consistent set of parameters for the definition of a new GRS for the term 2019-2023. Objectives of this working group are to publish a new set of defining parameters for a modern GRS; to calculate all the necessary derived parameters in a consistent way; to prepare an IAG resolution towards the replacement of the GRS80; and to provide all needed transformation procedures between the old and the new GRS (Marti, 2019).

\section{Reference network for the establishment of the International Height Reference Frame (IHRF)}

It is proposed that the IHRF follows the same structure as the ITRF: a global network with regional and national densifications, whose geopotential numbers (see Eq. [1]) referring to the global IHRS are known. To advance in this goal, the GGOS-FA-UHS installed the joint working group Strategy for the Realisation of the IHRS for the term 2015-2019 (Sánchez, 2019). This working group was supported by the IGFS, the IAG Commissions 1 and 2 (Reference Frames and Gravity field), the Inter-commission Committee on Theory (ICCT), the regional sub-commissions for reference frames and geoid modelling, and both GGOS Bureaus (Networks and Observations and Products and Standards). In particular, there was a strong cooperation with

- $\quad$ IAG JWG 2.2.2: The 1-cm geoid experiment (Wang and Forsberg, 2019)

- IAG SC 2.2: Methodology for geoid and physical height systems (Ågren and Ellmann, 2019)

- ICCT JSG 0.15: Regional geoid/quasi-geoid modelling - Theoretical framework for the subcentimetre accuracy (Huang and Wang, 2019)

- IAG JWG 2.1.1: Establishment of a global absolute gravity reference system (Wziontek and Bonvalot, 2019).

A brainstorming and definition of action items took place at a working group meeting carried out during the International Symposium on Gravity, Geoid and Height Systems 2016 (GGHS2016) in Thessaloniki (Greece) in Sep 2016. This meeting was attended by 70 colleagues and allowed us to identify the activities to be faced immediately (Sánchez, 2016b). A main output are the criteria for the selection of IHRF reference stations:

- GNSS continuously operating reference stations to detect reference frame deformations;

- Co-location with fundamental geodetic observatories to ensure a consistent connection between geometric coordinates, potential and gravity values, and reference clocks (to support the implementation of the GGRF);

- Co-location with reference stations of the International Gravity Reference Frame (IGRF): the IGRF and IHRF station selection for the co-location of this two reference frames is a contribution of IAG JWG 2.1.1 (Wziontek and Bonvalot, 2019);

- Preference of stations belonging to the ITRF and the regional reference frames (like SIRGAS, EPN, APREF, etc.);

- Co-location with reference tide gauges and connection to the national levelling networks to facilitate the vertical datum unification; 
Sánchez L, Barzaghi R (2020). Activities and plans of the GGOS Focus Area Unified Height System. EGU General Assembly 2020, EGU2020-8625, https://doi.org/10.5194/egusphere-egu2020-8625.

(C) Author(s) 2020.

(0) This work is distributed under the Creative Commons Attribution 4.0 License.

- Availability of terrestrial gravity data around the IHRS reference stations as main requirement for high-resolution gravity field modelling (i.e., precise estimation of potential values).

During the GGOS Days 2016 (Boston (MA), USA, Oct 2016), a preliminary station selection for the IHRF was performed (Sánchez, 2016c). This selection was based on a global network with worldwide distribution, including a core network (to ensure sustainability and long-term stability of the reference frame) and regional/national densifications (to provide local accessibility to the global frame). Based on the conclusions of the meetings in Thessaloniki and Boston, regional and national experts were asked to evaluate whether the preliminary selected sites are suitable to be included in the IHRF (availability of gravity data or possibilities to survey them); and to propose additional geodetic sites to improve the density and distribution of the IHRF stations in their regions/countries. After the feedback from the regional/national experts, the first approximation to the IHRF reference network is based on about 170 stations (Sánchez et al., 2019a). Currently, this station selection is regularly refined in agreement with changes/updates of other geodetic reference frames (ITRF and IGRF and their densifications). Figure 2 shows the IHRF station distribution and the co-location with SLR, VLBI, DORIS, IGRF, tide gauges and levelling networks' stations.

\section{Determination of potential values as IHRS coordinates}

After the preliminary station selection for the IHRF reference network, efforts concentrated on the computation of station potential values and the assessment of their accuracy. Different approaches were evaluated (Sánchez et al., 2017):

- As some national/regional experts provided us with terrestrial gravity data around some IHRF sites, a direct computation of potential values was performed using a combination of terrestrial gravity data and different global gravity models (GGM) as well as different mathematical formulations (least-squares collocation, FFT, radial basis functions, etc.).

- Computation of potential values by national/regional experts responsible for the geoid modelling using their own data and methodologies.

- Computation of potential values based on GGM of high-degree (like XGM2016 (Pail et al., 2017; 2018), EIGEN-6C4 (Förste et al., 2014), EGM2008 (Pavlis et al., 2012; 2013), etc.).

- Recovering potential values from existing local (quasi-)geoid models.

The comparison of the results showed discrepancies up to the dm-level (Sánchez et al., 2017). The main conclusions of this experiment were:

- The use of only GGMs is (at present) not suitable for the estimation of precise potential values. GGMs may be used if there is no other way to determine potential values.

- A standard procedure for the computation of potential values may be not appropriate as

- different data availability and different data quality exist around the world;

- regions with different characteristics require particular approaches (e.g. modification of kernel functions, size of integration caps, geophysical reductions like GIA, etc.).

- A centralised computation (like in the ITRF) is complicated due to the restricted accessibility to terrestrial gravity data. 
Sánchez L, Barzaghi R (2020). Activities and plans of the GGOS Focus Area Unified Height System. EGU General Assembly 2020, EGU2020-8625, https://doi.org/10.5194/egusphere-egu2020-8625.
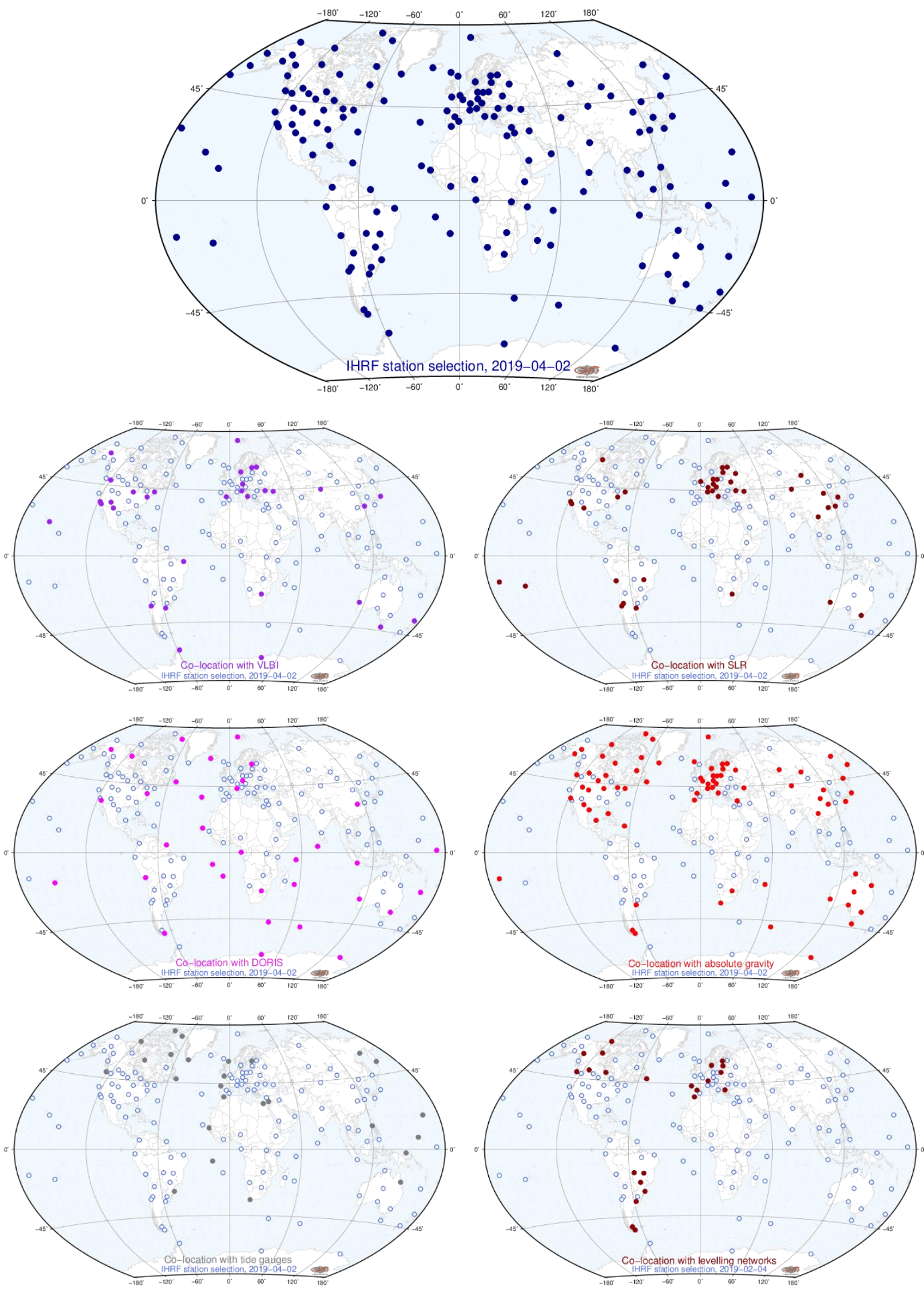

Fig 2. IHRF reference stations and the co-location with Very Long Baseline Interferometry (VLBI) stations, Satellite Laser Ranging (SLR) stations, Doppler Orbitography and Radiopositioning Integrated by Satellite (DORIS) stations, absolute gravity (IGRF) stations, tide gauges and levelling networks' stations. 
Sánchez L, Barzaghi R (2020). Activities and plans of the GGOS Focus Area Unified Height System. EGU General Assembly 2020, EGU2020-8625, https://doi.org/10.5194/egusphere-egu2020-8625.

(C) Author(s) 2020.

(0) This work is distributed under the Creative Commons Attribution 4.0 License.

To overcome these inconveniences, during the IAG-IASPEI Joint Scientific Assembly (Kobe, Japan, Aug 2017) was agreed to initiate a new experiment towards:

- The computation of IHRF coordinates using exactly the same input data and the own methodologies (software) of colleagues involved in the gravity field modelling, and

- The comparison of the results, to identify a set of standards that allow to get as similar and compatible results as possible.

In the same IAG-IASPEI 2017 Assembly, J. Ågren (Chair of IAG SC 2.2; Ågren and Ellmann (2019)) and J. Huang (Chair of ICCT JSG 0.15, Huang and Wang (2019) proposed to establish an interaction with the JWG 2.2.2 (chaired by Y.M. Wang, Wang and Forsberg (2019). Aim of JWG 2.2.2 was the computation and comparison of geoid undulations using the same input data and the own methodologies/software of colleagues involved in the geoid computation. The comparison of the results should highlight the differences caused by disparities in the computation methodologies. In this frame, it was decided to extend the geoid experiment to the computation of station potential values as IHRS coordinates. With this proposal, the US NGS/NOAA agreed to provide terrestrial gravity data, airborne gravity, and digital terrain model for an area of about $500 \mathrm{~km} \times 800 \mathrm{~km}$ in Colorado, USA (Fig. 3).
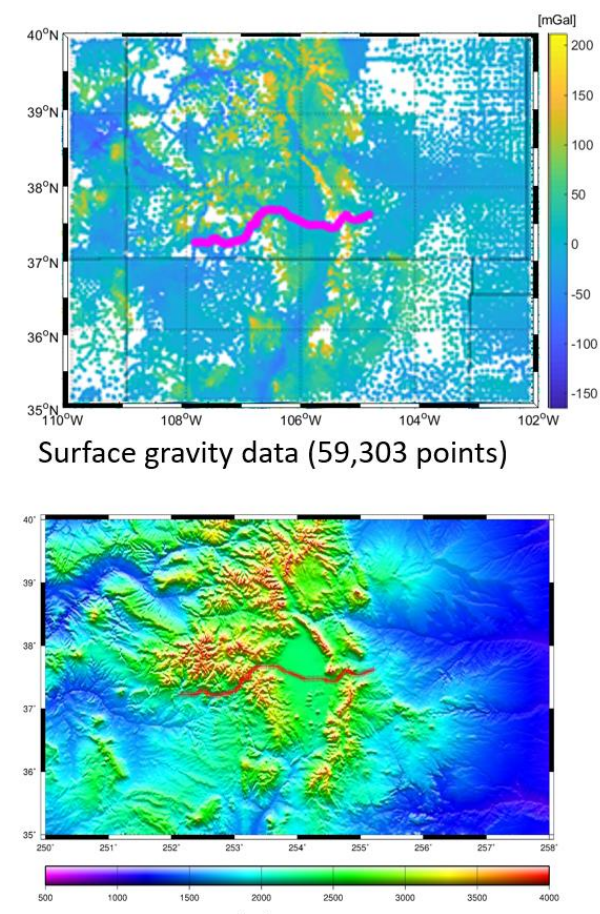

Terrain model: SMRT V4.1

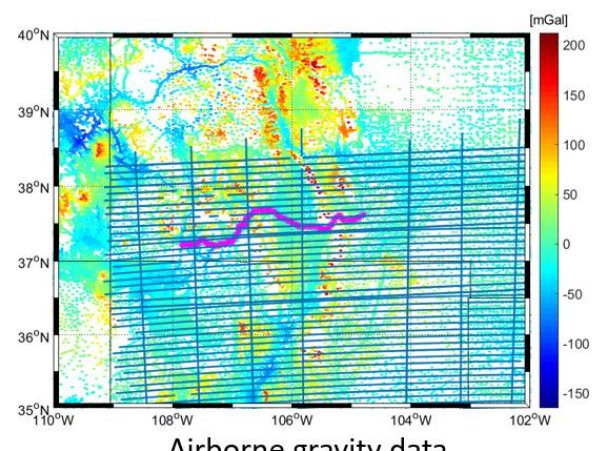

Airborne gravity data (41 lines E-W, 7 lines N-S)

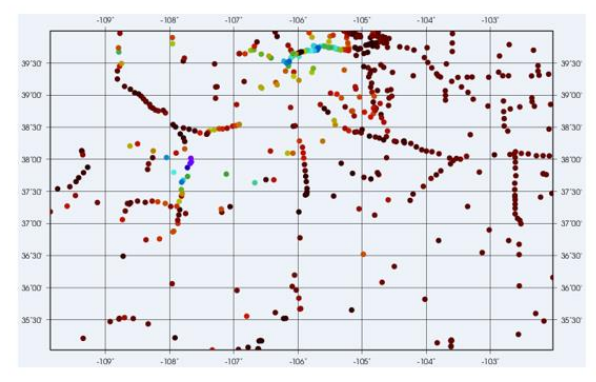

NGS historical GPS/levelling (510 points)

Fig 3. Data provided by the US NGS/NOAA for the Colorado experiment. The red line represents the validation profile of the Geoid Slope Validation Survey 2017 (GSVS17). For validation, potential differences inferred from first order levelling and gravity corrections along this line are to be compared with potential differences inferred from the different Colorado solutions.

With the NGS/NOAA data, different groups working on the determination of IHRF coordinates should compute potential values for some virtual geodetic stations located in that region. Afterwards, the results individually obtained should be compared with the Geoid Slope Validation Survey 2017 (GSVS17), which will provide potential differences inferred from first order levelling measurements 
Sánchez L, Barzaghi R (2020). Activities and plans of the GGOS Focus Area Unified Height System. EGU General Assembly 2020, EGU2020-8625, https://doi.org/10.5194/egusphere-egu2020-8625.

(C) Author(s) 2020.

(c) This work is distributed under the Creative Commons Attribution 4.0 License.

and gravity corrections along a validation line (see red line in Fig. 3). The Colorado data were distributed in Feb. 2018, together with a document summarising a minimum set of basic requirements (standards) for the computations in order to get as similar and compatible results as possible (Sánchez et al. 2018a). As a first step, eight groups completed geoid computations and discussed the results at the Gravity, Geoid and Height Systems (GGHS2018) Symposium (Copenhagen, Denmark, Sep 2018). These first preliminary results identified the largest sources of disagreement in handling the so-called zero-degree term, the conversion between geoid undulations and height anomalies, and the initial processing of the airborne gravity data (Wang et al., 2018; Sánchez et al. 2018b). Consequently, it was agreed to refine the explanation of the zero-degree term in the set of basic processing requirements, to recommend the use of consistent orthometric hypotheses for the geoid computation and the transformation from height anomalies to the geoid undulations, and to use the NOAA/NGS preprocessed (cleaned) version of the GRAV-D data (down sampling from $20 \mathrm{~Hz}$, de-biased data). Afterwards, additional groups joined the experiment and two full iterations were completed between Oct 2018 and July 2019. During the iteration process, nine groups refined their models twice.

Figure 4 presents the comparison of the potential values delivered by the different groups. For the sake of facility, the potential values are converted to normal heights after subtracting the reference potential $W_{0}$ from the point-wise potentials. The results show that twelve of fourteen solutions agree within $\pm 1 \mathrm{~cm}$ to $\pm 2 \mathrm{~cm}$ in terms of standard deviation with respect to the mean value (Sánchez et al., 2019a). These discrepancies only reflect the disagreement between computation methods as the input data are assumed free of error and a proper error propagation analysis is not performed yet. However, it is evident that the discrepancies between the different solutions are highly correlated with the topography, suggesting further investigations on the handling of terrain gravity effects (model and strategy). Based on these outcomes, the next activities concentrate on generating a detailed document with standards for the determination of potential values; on investigating better strategies for the modelling of topographic effects, the determination of potential changes with time, and reliable approaches for the accuracy assessment.

\begin{tabular}{|lrlrrrrr|}
\hline & Mean & \pm & STD & \multicolumn{5}{c|}{ Range } & \\
sol1 & 1.0 & \pm & 1.6 & 6.6 & $(-3.5$ & $\ldots$ & $3.1)$ \\
sol2 & -1.0 & \pm & 2.1 & 9.5 & $(-4.4$ & $\ldots$ & $5.1)$ \\
sol3 & -0.1 & \pm & 1.0 & 5.8 & $(-3.2$ & $\ldots$ & $2.6)$ \\
sol5 & 1.0 & \pm & 1.8 & 9.4 & $(-1.6$ & $\ldots$ & $7.9)$ \\
sol6 & 0.4 & \pm & 1.0 & 5.3 & $(-2.7$ & $\ldots$ & $2.6)$ \\
sol7 & -1.4 & \pm & 2.3 & 9.9 & $(-5.1$ & $\ldots$ & $4.7)$ \\
sol8 & 0.0 & \pm & 1.8 & 6.5 & $(-4.1$ & $\ldots$ & $2.4)$ \\
sol9 & 1.1 & \pm & 2.2 & 14.0 & $(-6.3$ & $\ldots$ & $7.7)$ \\
sol10 & 0.0 & \pm & 1.2 & 7.5 & $(-3.2$ & $\ldots$ & $4.3)$ \\
sol11 & 0.0 & \pm & 1.1 & 5.6 & $(-3.2$ & $\ldots$ & $2.4)$ \\
sol12 & -0.9 & \pm & 1.4 & 7.5 & $(-5.1$ & $\ldots$ & $2.4)$ \\
sol14 & 0.4 & \pm & 1.0 & 5.0 & $(-2.4$ & $\ldots$ & $2.6)$ \\
\hline
\end{tabular}

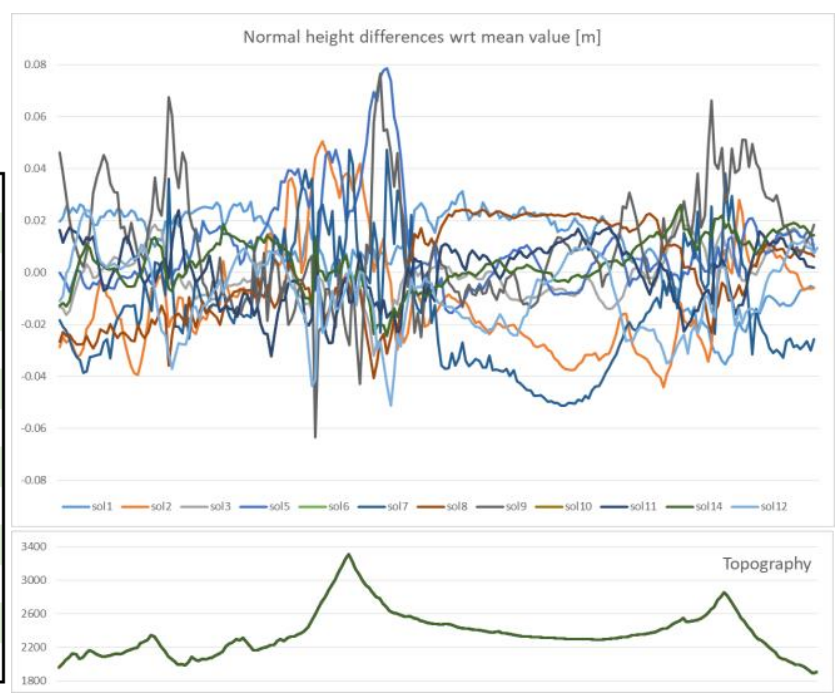

Fig 4. Comparison of potential values obtained by different methods for the regional gravity field modelling. The comparison is made in terms of normal heights. 
Sánchez L, Barzaghi R (2020). Activities and plans of the GGOS Focus Area Unified Height System. EGU General Assembly 2020, EGU2020-8625, https://doi.org/10.5194/egusphere-egu2020-8625.

(C) Author(s) 2020.

(a) This work is distributed under the Creative Commons Attribution 4.0 License.

Based on the outcomes of the Colorado experiment, during the 2019 IUGG General Assembly, the IAG released a new resolution promoting the implementation of the IHRS at regional and national levels; see IAG Resolution No. 3, 2019 (Annex B). Additionally, at present (as of Apr 2020), a Journal of Geodesy special issue on Reference Systems in Physical Geodesy is being prepared. This special issue should include key contributions for the establishment of the IHRS/IHRF and the IGRS/IGRF and the scientific description of the individual solutions contributing to the Colorado experiment.

\section{Vertical datum unification for the International Height Reference System (IHRS)}

A main component of the IHRS realisation is the integration of the existing height systems into the global one; i.e. existing physical heights (or geopotential numbers) should be referred to one and the same reference level realised by the conventional $W_{0}$. This procedure is known as vertical datum unification and its main result are the potential differences (called vertical datum parameters) between the local and the global reference levels. The motivation for the vertical datum unification rises from the fact that the local physical height systems have been the reference for height determination during the last 150 years and they provide a higher accuracy in contiguous areas than the combination of ellipsoidal heights $(h)$ with quasi-geoid $(\zeta)$ or geoid $(N)$ models, i.e., $H=h-N$ or $H^{*}$ $=h-\zeta$, particularly in those regions with sparse terrestrial gravity data. If the local height systems are appropriately integrated into the IHRS, the existing vertical data can be modernised and be useful for geodetic applications of global context.

Sánchez and Sideris (2017) rigorously derive the observation equations for the vertical datum unification in terms of potential quantities based on the geodetic boundary value problem (GBVP) approach (cf. Rummel and Teunissen, 1988; Heck and Rummel, 1990; Lehmann, 2000; Sideris, 2014; Rummel et al., 2014). Those observation equations are then empirically evaluated for the vertical datum unification of the North American and South American height systems. In the first case, simulations performed in North America provide numerical estimates about the impact of omission errors and direct and indirect effects on the vertical datum parameters. In the second case, a combination of local geopotential numbers, ITRF coordinates, satellite altimetry observations, tide gauge registrations, and high-resolution gravity field models is performed to estimate the level differences between the South American height systems and the global level $W_{0}$. Results show that indirect effects vanish when a satellite-only gravity field model with a degree higher than $n \geq 180$ is used for the solution of the GBVP. However, the component derived from satellite-only global gravity models has to be refined with terrestrial gravity data to minimise the omission error and its effect on the vertical datum parameter estimation. The empirical evaluations demonstrate that the vertical datum unification should be based on geodetic stations of highest quality and standardised geodetic data; for example, geometric coordinates should refer to the same ITRF and be given in the same tide system and reference epoch as the geopotential numbers and gravity field model. After a standardisation of the input data used in the unification of the South American height systems and a rigorous error propagation analysis, it is evident that the vertical datum parameters can be estimated with accuracy better than $\pm 5 \mathrm{~cm}$ in well-surveyed regions and some decimetres $( \pm 40 \mathrm{~cm}$ ) in sparsely surveyed regions. Sánchez and Sideris (2017) also provide detailed guidelines for the appropriate data treatment when the integration of a local vertical datum into the IHRS is desired. 
Sánchez L, Barzaghi R (2020). Activities and plans of the GGOS Focus Area Unified Height System. EGU General Assembly 2020, EGU2020-8625, https://doi.org/10.5194/egusphere-egu2020-8625.

\section{Next steps: A first solution for the IHRF and an operational infrastructure to guarantee the long-term sustainability of the IHRF}

Based on the outcomes of the Colorado experiment, we are working on the compilation of a detailed document with standards for the determination of potential values. This would be helpful for the consistent establishment of global, regional and local IHRF reference stations. Nevertheless, it is still necessary to investigate better strategies for the modelling of topographic effects, the determination of potential changes with time, and reliable approaches for the accuracy assessment. To face these challenges, the IAG Commission 2 (Gravity Field), the IAG ICCT, and the GGOS-FA-UHS together with the IGFS installed three working/study groups for the term 2019-2023:

- IAG Commission 2 working group Error assessment of the 1-cm geoid experiment, chaired by M Willberg (Germany) and T Jiang (China).

- IAG ICCT study group Geoid/quasi-geoid modelling for realisation of the geopotential height datum, chaired by J Huang (Canada).

- GGOS-FA-UHS and IGFS working group Implementation of the International Height Reference Frame (IHRF), chaired by L Sánchez (Germany) and R Barzaghi (Italy).

Simultaneously, we aim at computing a first static solution for the IHRF core network to evaluate the achievable accuracy under the present conditions (data availability, computation methods, etc.) and to identify key actions to improve the determination of the IHRS/IHRF coordinates. As already mentioned, a centralised computation of $W$ is (still) unviable due to the restricted accessibility to terrestrial gravity data and elevation models of high-resolution. Consequently, to exploit at maximum the existing data to get as accurate as possible potential values, national/regional experts in the gravity field (or geoid) modelling should be involved in the determination of the IHRS/IHRF coordinates. As a rigorous standardisation in the data processing seems to be not suitable (because the different gravity data conditions and quality around the world), we need to investigate strategies for the quality assessment of the individual computations. In this regard, the GGOS-FA-UHS and the IGFS are considering different possibilities:

- Installation of auxiliary stations close $(20 \ldots 100 \mathrm{~km})$ to the core IHRF stations connected by levelling of high precision to have independent data (potential differences) for evaluation;

- Redundancy in the computation: an IGFS analysis centre or IGFS associates could be provided with local data to determine potential values to be compared with the local results, or

- Calibration of the computation methods used by national/regional experts: determination of potential values using a certain set of input data and comparison with results obtained by other approaches (like in the Colorado experiment).

This demands in addition to investigate the best way to establish an IHRS/IHRF element within the IGFS to ensure the maintenance and availability of the IHRF. This implies regular updates of the IHRFyyy to take account for new stations, coordinate changes with time, improvements in the estimation of coordinates (more observations, better standards, better models, better computation algorithms, etc.), geodetic products associated to the IHRF (description and metadata), and the organisational and 
Sánchez L, Barzaghi R (2020). Activities and plans of the GGOS Focus Area Unified Height System. EGU General Assembly 2020, EGU2020-8625, https://doi.org/10.5194/egusphere-egu2020-8625.

(C) Author(s) 2020.

(a) This work is distributed under the Creative Commons Attribution 4.0 License.

operational infrastructure to ensure the IHRF sustainability. These aspects are discussed in detail by Sánchez et al. (2019b) and Barzaghi et al. (2020).

\section{Closing remarks}

The implementation of a global reference system for physical heights as the IHRS is a big challenge and requires the support of a wide scientific community. Thus, the installation of the IHRS/IHRF is only possible within a global and structured organisation like the IAG. A lot of work is required. A source of inspiration is the ITRF. If we compare the first published version of the ITRF (ITRF89; Boucher and Altamimi, 1991) with the most recent one (ITRF2014; Altamimi et al., 2016), the huge improvement is evident. The ITRF89 included station positions only (station velocities were neglected), there were as many coordinate sets for each station as analysis centres processing that station, the conversion to ellipsoidal coordinates used arbitrary values for the ellipsoid constants (the GRS80 was not considered), station positions presented a precision from 11 to $60 \mathrm{~mm}$, etc. The ITRF2014 is totally different: standardised computation, various processing and combination centres, station positions and motions with accuracy at the mm-level. Following this example, we are confident that once we have implemented a first approximation to the IHRF, it can be improved by considering more and more details that at the beginning may represent unsolvable obstacles.

\section{Acknowledgements}

The advancements described in this report were possible thanks to the support of many colleagues. Their contribution is deeply acknowledged: $M$ Véronneau, J Huang, YM Wang, J Ågren, $Q$ Liu, $M$ Willberg, H Denker, R Pail, V Lieb, J Ihde, M Sideris, S Claessens, M Filmer, VN Grigoriadis, GS Vergos, DA Natsiopoulos, B Erol, M Serkan Isik, S Erol, M Varga, T Bašic, M Pitonák, P Novák, D Carrion, I Oshchepkov, D Roman, K Choi, K Ahlgren, R Ruddick, M Amos, SRC de Freitas, JR Chire Chira, DA Piñón, C Estrella, A Álvarez, A Echalar Rivera, D Avalos-Naranjo, S Costa, $R$ Luz, M Schmidt, J Mäkinen, D Blizkow, ACOC de Matos, N Suárez, J Krynski, U Marti, K Matsuo, H Abd-Elmotaal, M Poutanen, PA Vaquero Fernández, $H$ Wziontek, V Mackern, W Martínez, R Forsberg, I Liepinš, $T$ Jiang, JL CarriónSánchez, X Li, EL Nicacio, R Dalazoana, VG Ferreira.

\section{References}

Ågren J, Ellmann A (2019). Report of the Sub-commission 2.2: Methodology for Geoid and Physical Height Systems, Reports 2015-2019 of the International Association of Geodesy (IAG), Travaux de I'AIG Vol. 41: 155-160.

Altamimi Z, Rebischung P, Métivier L, Collilieux X (2016). ITRF2014: A new release of the International Terrestrial Reference Frame modeling nonlinear station motions, J Geophys Res Solid Earth 121: 6109-6131, https://doi.org/10.1002/2016JB013098.

Angermann D, Gruber T, Gerstl M, Heinkelmann R, Hugentobler U, Sánchez L, Steigenberger P. (2016). GGOS Bureau of Products and Standards: Inventory of standards and conventions used for the generation of IAG products. In: Drewes H., Kuglitsch F., Adám J., Rózsa S. (Eds.) The Geodesist's Handbook 2016. Journal of Geodesy 90: 1095-1156, https://doi.org/10.1007/s00190-016-0948-z.

Angermann D, Gruber T, Gerstl M, Heinkelmann R, Hugentobler U, Sánchez L, Steigenberger P (2018). GGOS Bureau of Products and Standards: Recent Activities and Future Plans. International Association of Geodesy Symposia Series, 149: 153-159, https://doi.org/10.1007/1345_2018_28. 
Sánchez L, Barzaghi R (2020). Activities and plans of the GGOS Focus Area Unified Height System. EGU General Assembly 2020, EGU2020-8625, https://doi.org/10.5194/egusphere-egu2020-8625.

(C) Author(s) 2020.

(a) This work is distributed under the Creative Commons Attribution 4.0 License.

Angermann D, Gruber T, Gerstl M, Heinkelmann R, Hugentobler U, Sánchez L, Steigenberger P (2019). GGOS Bureau of Products and Standards. In: Drewes H., Kuglitsch F. (Eds.), Reports 2015-2019 of the International Association of Geodesy (IAG), Travaux de I'AIG Vol. 41: 570-757.

Barzaghi R, Sánchez L, Vergos G (2020). Operational infrastructure to ensure the long-term sustainability of the IHRS/IHRF. EGU General Assembly 2020, EGU2020-7961, https://doi.org/10.5194/egusphere-egu2020-7961.

Boucher C, Altamimi Z (1991). ITRF89 and other realizations of the IERS Terrestrial Reference System for 1989. IERS Technical Note 6, Paris, Central Bureau of IERS - Observatoire de Paris, $137 \mathrm{pp}$.

Burša M, Kouba J, Raděj K, True S, Vatrt V, Vojtíšková M (1998). Mean Earth's equipotential surface from TOPEX/Poseidon altimetry. Studia geoph et geod 42: 456-466, https://doi.org/doi:10.1023/A:1023356803773.

Čunderlík R, Mikula K (2009). Numerical solution of the fixed altimetry-gravimetry BVP using the direct BEM formulation. International Association of Geodesy Symposia Series, 133: 229-236, https://doi.org/10.1007/978-3-540-85426-5 27.

Čunderlík R, Minarechová Z, Mikula K (2014). Realization of WHS based on the static gravity field observed by GOCE. International Association of Geodesy Symposia Series, 141: 211-220, https://doi.org/10.1007/978-3319-10837-7 27.

Dayoub N, Edwards SJ, Moore P (2012). The Gauss-Listing potential value Wo and its rate from altimetric mean sea level and GRACE. Journal of Geodesy 86(9): 681-694, https://doi.org/10.1007/s00190-012-1547-6.

Drewes H, Kuglitsch F, Ádám J, Rózsa S (2016). Geodesist's Handbook 2016, Journal of Geodesy 90: 907. https://doi.org/10.1007/s00190-016-0948-z.

Forsberg R, Barzaghi ., Kenyon ., Marson I. (2015). International Gravity Field Service (IGFS). In: Drewes H., Hornik H. (Eds.) Reports 2011-2015 of the International Association of Geodesy (IAG), Travaux de I'AIG 39: 477-484.

Förste Ch, Bruinsma SL, Abrikosov O, Lemoine J-M, Marty JC, Flechtner F, BalminoG, Barthelmes F and Biancale $\mathrm{R}$ (2014). EIGEN-6C4 The latest combined global gravity field model including GOCE data up to degree and order 2190 of GFZ Potsdam and GRGS Toulouse. GFZ Data Services. http://doi.org/10.5880/icgem.2015.1.

Groten E (1999). Report of the International Association of Geodesy Special Commission SC3: fundamental constants. XXII IAG General Assembly, Birmingham.

Groten E (2004). Fundamental parameters and current (2004) best estimates of the parameters of common relevance to Astronomy, Geodesy and Geodynamics. The Geodesist's Handbook 2004. Journal of Geodesy 77 : 724-731, https://doi.org/10.1007/s00190-003-0373-y.

Heck B, Rummel R (1990). Strategies for solving the vertical datum problem using terrestrial and satellite geodetic data. Association of Geodesy Symposia Series, 104: 116-128, https://doi.org/10.1007/978-1-4684-7098-7 14.

Huang J, Wang YM (2019). Report of Joint Study Group 0.15: Regional geoid/quasigeoid modelling - theoretical framework for the sub-centimetre, Reports 2015-2019 of the International Association of Geodesy (IAG), Travaux de I'AIG Vol. 41: 495-499.

IAG (2017). Description of the Global Geodetic Reference Frame. Position paper adopted by the IAG Executive Committee in April 2016. Journal of Geodesy 91:113-116, https://doi.org/10.1007/s00190-016-0994-6.

Ihde J (2007). Inter-Commission project 1.2: Vertical Reference Frames. Final report for the period 2003-2007. In: Drewes H., Hornik H. (Eds). IAG Commission 1 - Reference Frames, Report 2003 -2007. DGFI, Munich. Bulletin No. 20: $57-59$.

Ihde J, Amos M, Heck B, Kersley B, Schöne T, Sánchez L Drewes H (2007). Conventions for the definitions and realization of a conventional vertical reference system (CVRS). Available at https://ihrs.dgfi.tum.de/fileadmin/ICP12/CVRS conventions final 20070629.pdf. Last accessed 2020-04-12.

Ihde J, Barzaghi R, Marti U, Sánchez L, Sideris M, Drewes H, Förste C, Gruber T, Liebsch G, Pail R (2015). Report of the Ad-hoc Group on an International Height Reference System (IHRS). In: Drewes H., Hornik H. (Eds.) Reports 2011-2015 of the International Association of Geodesy (IAG), Travaux de I'AIG 39: 549-557.

Ihde J, Sánchez L, Barzaghi R, Drewes H, Foerste C, Gruber T, Liebsch G, Marti U, Pail R, Sideris M (2017). Definition and proposed realization of the International Height Reference System (IHRS). Surveys in Geophysics, 38(3), 549-570, https://doi.org/10.1007/s10712-017-9409-3.

Lehmann R (2000). Altimetry-gravimetry problems with free vertical datum, Journal of Geodesy, 74: 327-334, https://doi.org/10.1007/s001900050290. 
Sánchez L, Barzaghi R (2020). Activities and plans of the GGOS Focus Area Unified Height System. EGU General Assembly 2020, EGU2020-8625, https://doi.org/10.5194/egusphere-egu2020-8625.

(C) Author(s) 2020.

(c) (1) This work is distributed under the Creative Commons Attribution 4.0 License.

Ma C, Feissel M (1997). Definition and realization of the International Celestial Reference System by VLBI astrometry of extragalactic objects. IERS Technical Note 23, Paris, Central Bureau of IERS - Observatoire de Paris, $282 \mathrm{p}$.

Marti U (2019). BPS Working Group: Towards a consistent set of parameters for the definition of a new GRS: Terms of Reference. Proposal to be included in the 2020 Geodesist's Handbook.

Marti U, Richard Ph, Germak A, Vitushkin L, Pálinkáš V, Wilmes H (2014). CCM-IAG Strategy for Metrology in Absolute Gravimetry. Available at http://www.bipm.org/wg/CCM/CCM-WGG/Allowed/2015meeting/CCM IAG Strategy.pdf. Last accessed 2020-04-12.

Moritz H (1980). Geodetic Reference System 1980. In: Geodesist's Handbook 1980. International Association of Geodesy (IAG).

Moritz H (2000). Geodetic Reference System 1980, Journal of Geodesy, 74: 128-133, https://doi.org/10.1007/s001900050278.

NIMA (1997). Department of Defense World Geodetic System 1984, its definition and relationships with local geodetic systems. National Imagery and Mapping Agency, Technical Report TR8350.2, 175 pp.

Oshchepkov I (2018). Geodetic reference system consistent with the IHRF Wo value. Symposium Gravity, Geoid and Height Systems 2018 (GGHS2018), Copenhagen, Denmark, Sep 2018.

Oshchepkov I (2019). 40 Years of the GRS80: Do We Need a New Ellipsoid? 2019 General Assembly of the International Union for Geodesy and Geophysics (IUGG), Montreal, Canada, July 2019.

Pail R, Fecher T, Barnes D, Factor J, Holmes S, Gruber T, Zingerle P (2017). The experimental gravity field model XGM2016. GFZ Data Services, http://doi.org/10.5880/icgem.2017.003.

Pail R, Fecher T, Barnes D, Factor JF, Holmes SA, Gruber T, and Zingerle P (2018). Short note: the experimental geopotential model XGM2016, Journal of Geodesy, 92: 443, https://doi.org/10.1007/s00190-017-1070-6.

Pavlis N-K, Holmes SA, Kenyon SC, and Factor JK (2012). The development of the Earth Gravitational Model 2008 (EGM2008), Journal of Geophysical Research 117:B04406, https://doi.org/10.1029/2011JB008916.

Pavlis N-K, Holmes SA, Kenyon SC, and Factor JK (2013). Correction to "The development of the Earth Gravitational Model 2008 (EGM2008)", Journal of Geophysical Research 118:2633, https://doi.org/10.1002/igrb.50167.

Petit G, Luzum B (2010). IERS Conventions (2010). IERS Technical Note 36, Frankfurt am Main: Verlag des Bundesamts für Kartographie und Geodäsie, 179 pp., ISBN 3-89888-989-6.

Rummel R, Teunissen P (1988). Height datum definiton, height datum connection and the role of the geodetic boundary value problem, Bull. Géod. 62: 477-498, https://doi.org/10.1007/BF02520239.

Rummel R, Gruber Th, Ihde J, Liebsch G, Rülke A, Schäfer U, Sideris M, Rangelova E, Woodworth Ph, Hughes Ch (2014). STSE-GOCE+, Height system unification with GOCE, Doc. No. GO-HSU-PL-002, Issue 1, 24-02-2014.

Sánchez L (2008) Approach for the establishment of a global vertical reference level. International Association of Geodesy Symposia Series, 132: 119-125, https://doi.org/10.1007/978-3-540-74584-6 18.

Sánchez L (2012). Towards a vertical datum standardisation under the umbrella of Global Geodetic Observing System. Journal of Geodetic Science, 2(4): 325-342, https://doi.org/10.2478/v10156-012-0002-x.

Sánchez L (2015). Joint Working Group 0.1.1: Vertical Datum Standardisation (JWG 0.1.1). In: Drewes H., Hornik H. (Eds.) Reports 2011-2015 of the International Association of Geodesy (IAG), Travaux de I'AIG 39: 402-404.

Sánchez L (2016a). GGOS Focus Area 1: Unified Height System - Terms of reference. In: Drewes H, Kuglitsch F, Ádám J, Rózsa S (2016). Geodesist's Handbook 2016, Journal of Geodesy 90: 1091. https://doi.org/10.1007/s00190-016-0948-z.

Sánchez L (2016b). Working Group on the Strategy for the Realization of the International Height Reference System (IHRS): Brainstorming and definition of action items. Splinter meeting at the International Symposium on Gravity, Geoid and Height Systems $2016 \quad$ (GGHS2016), https://ihrs.dgfi.tum.de/fileadmin/JWG 2015/SP WG IHRS Realization with Comments from the Splinte r Meeting.pdf. Last accessed 2020-04-12.

Sánchez L (2016c). International Height Reference System (IHRS): Required measurements and expected products. GGOS Days 2016, Cambridge (MA), https://ihrs.dgfi.tum.de/fileadmin/JWG 2015/Sanchez IHRS Obs Prod GGOS2016 2.pdf. Last accessed 2020-04-12. 
Sánchez L, Barzaghi R (2020). Activities and plans of the GGOS Focus Area Unified Height System. EGU General Assembly 2020, EGU2020-8625, https://doi.org/10.5194/egusphere-egu2020-8625.

(C) Author(s) 2020.

(a) This work is distributed under the Creative Commons Attribution 4.0 License.

Sánchez L (2019). Report of the GGOS Focus Area "Unified Height System" and the Joint Working Group 0.1.2: Strategy for the Realization of the International Height Reference System (IHRS), Reports 2015-2019 of the International Association of Geodesy (IAG), Travaux de I'AIG Vol. 41: 583-592.

Sánchez L, Dayoub N, Čunderlík R, Minarechová Z, Mikula K, Vatrt V, Vojtíšková M, Šíma Z (2014). Wo estimates in the frame of the GGOS Working Group on Vertical Datum Standardisation. International Association of Geodesy Symposia Series, 141: 203-210, https://doi.org/10.1007/978-3-319-10837-7 26.

Sánchez L, Čunderlík R, Dayoub N, Mikula K, Minarechová Z, Šíma Z, Vatrt V, Vojtíšková M (2016). A conventional value for the geoid reference potential $W_{0}$. Journal of Geodesy, 90(9): 815-835, https://doi.org/10.1007/s00190-016-0913-x.

Sánchez L, Sideris MG (2017). Vertical datum unification for the International Height Reference System (IHRS). Geophysical Journal International, 209(2), 570-586, https://doi.org/10.1093/gji/ggx025.

Sánchez L, Ågren J, Huang J, Wang YM, Forsberg R (2018a). Basic agreements for the computation of station potential values as IHRS coordinates, geoid undulations and height anomalies within the Colorado $1 \mathrm{~cm}$ geoid experiment. Available at https://ihrs.dgfi.tum.de/fileadmin/JWG 2015/Colorado Experiment Basic req V0.5 Oct30 2018.pdf. Last accessed 2020-04-13.

Sánchez L, Ågren J, Huang J, Véronneau M, Wang YM, Roman D, Vergos G, Abd-Elmotaal H, Amos M, Barzaghi R, Blitzkow D, Matos ACOC, Denker H, Filmer M, Claessens S, Oshchepkov I, Marti U, Matsuo K, Sideris M, Varga M, Willberg M, Pail R (2018b). Advances in the establishment of the International Height Reference Frame (IHRF). International Symposium on Gravity, Geoid and Height Systems 2018 (GGHS2018), Copenhagen, Denmark. Available at https://ihrs.dgfi.tum.de/fileadmin/JWG 2015/Sanchez et al IHRF GGSH2018 v3.pdf. Last accessed 2020-04-13.

Sánchez L, Ågren J, Huang J, Wang YM, Mäkinen J, Denker H, Ihde J, Abd-Elmotaal H, Ahlgren K, Amos M, Barzaghi R, Bašić T, Blitzkow D, Carrion D, Claessens S, Erol B, Erol S, Filmer M, Forsberg R, Grigoriadis VN, Serkan Işık M, Jiang T, Li X, Liu Q, Matos ACOC, Matsuo K, Novák P, Pail R, Pitoňák M, Roman D, Schmitd M, Sideris M, Varga M, Vergos GS, Véronneau M, Willberg M, Zhang C, Zingerle P (2019a). Advances in the realisation of the International Height Reference System. GGOS Days 2019 and Symposium SIRGAS2019, Rio de Janeiro, Brazil. Nov 11 - 14, 2019, http://www.sirgas.org/fileadmin/docs/Boletines/Bol24/42 Sanchez et al 2019 IHRS IHRF advances.pdf. Last accessed 2020-04-12.

Sánchez L, Barzaghi R, Vergos G (2019b). Operational infrastructure to ensure the long-term sustainability of the IHRS/IHRF. IUGG General Assembly 2019, Montreal, Canada. Available at https://mediatum.ub.tum.de/doc/1537756/1537756.pdf. Last accessed 2020-04-13.

Schöne T, Shum CK, Tamisiea M, Woodworth P (2015). GGOS Focus Area 3: Sea-Level Change, Variability and Forecasting. In: Drewes H., Hornik H. (Eds.) Reports 2011-2015 of the International Association of Geodesy (IAG), Travaux de I'AIG 39: 406-408.

Sideris MG (2014). Geodetic World Height System Unification, Handbook of Geomathematics, pp 1-16, https://doi.org/10.1007/978-3-642-27793-1 83-1.

Sideris MG, Ihde J (2012). GGOS Theme 1: Unified Height System - Terms of Reference. In: Drewes H, Geodesist's Handbook 2012. Journal of Geodesy 86: 923-924, https://doi.org/10.1007/s00190-012-0584-1.

Sideris MG, Ihde J (2015). GGOS Focus Area 1 Global Unified Height System. In: Drewes H., Hornik H. (Eds.) Reports 2011-2015 of the International Association of Geodesy (IAG), Travaux de I'AIG 39: 400-402.

Wang YM, Forsberg R, Sánchez L, Ågren J, Huang J (2018). Report on Colorado geoid comparisons. International Symposium on Gravity, Geoid and Height Systems 2018 (GGHS2018), Copenhagen, Denmark. Available at https://ihrs.dgfi.tum.de/fileadmin/JWG 2015/Wang report GGHS2018ColoradoGeoidReportMod.pdf. Last accessed 2020-04-13.

Wang YM, Forsberg R (2019). Report of the Joint Working Group 2.2.2: The $1 \mathrm{~cm}$ geoid experiment, Reports 20152019 of the International Association of Geodesy (IAG), Travaux de I'AIG Vol. 41: 178-179.

Wziontek H, Bonvalot S (2019). Report of the Joint Working Group 2.1.1: Establishment of a global absolute gravity reference system, Reports 2015-2019 of the International Association of Geodesy (IAG), Travaux de I'AIG Vol. 41: 147-152. 
Sánchez L, Barzaghi R (2020). Activities and plans of the GGOS Focus Area Unified Height System. EGU General Assembly 2020, EGU2020-8625, https://doi.org/10.5194/egusphere-egu2020-8625.

(C) Author(s) 2020.

(0) This work is distributed under the Creative Commons Attribution 4.0 License.

\section{Annex A IAG Resolution No. 1, 2015: Definition and Realization of an International Height Reference System (IHRS)}

Adopted by the IAG Council at the XXVIth IUGG General Assembly, Prague, Czech Republic, June 22 - July 2, 2015 (cf Drewes et al. 2016).

The International Association of Geodesy,

\section{Recognizing,}

- That to determine and to investigate the global changes of the Earth, the geodetic reference systems with long-term stability and worldwide homogeneity are required;

- That to detect sea level change of a few millimeters per year can only be possible when a stable spatial reference with globally high accuracy over a long period of time is realized; for this purpose, an integrated global geodetic reference frame with millimeter accuracy must be implemented; to reach this goal, the inconsistencies existing between analysis strategies, models, and products related to the Earth's geometry and gravity field must be solved;

- To accomplish both definition and realization of a height reference system (HRS) standards and conventions that allow a consistent definition and a reliable realization are required;

\section{Noting,}

- The results of the GGOS Theme 1 investigations for the definition and realiszation of an International Height Reference System in particular the conventions and the computations of the height reference level as the potential value $W_{0}$ at the geoid based on the newest global gravity field and sea surface models;

- The necessity of ensuring the reproducibility and interpretability of the reference value, the procedure applied for the determination of $W_{0}$ must be well documented including conventions and guidelines;

Resolves,

- The following conventions for the definition of an International Height Reference System (see note 1):

(1) The vertical reference level is an equipotential surface of the Earth gravity field with the geopotential value $W_{0}$ (at the geoid);

(2) Parameters, observations, and data shall be related to the mean tidal system/mean crust;

(3) The unit of length is the meter and the unit of time is the second (SI);

(4) The vertical coordinates are the differences $-\Delta W_{P}$ between the potential $W_{P}$ of the Earth gravity field at the considered points $P$, and the geoidal potential value $W_{0}$; the potential difference $-\Delta W_{P}$ is also designated as geopotential number $C_{P}:-\Delta W_{P}=C_{P}=W_{0}-W_{P}$;

(5) The spatial reference of the position $P$ for the potential $W_{P}=W(\mathbf{X})$ is related as coordinates $\mathbf{X}$ of the International Terrestrial Reference System;

- $W_{0}=62636853.4 \mathrm{~m}^{2} \mathrm{~s}^{-2}$ as realization of the potential value of the vertical reference level for the IHRS (see note 2).

Note 1: Ihde J, Barzaghi R, Marti U, Sánchez L, Sideris M, Drewes H, Foerste Ch, Gruber T, Liebsch G, Pail R: Report of the Ad-hoc Group on an International Height Reference System (IHRS); In: IAG Reports 2011-2015 (Travaux de líAIG Vol. 39), http://iag.dgfi.tum.de/index.php?id=329.

Note 2: Report of Joint Working Group 0.1.1: Vertical Datum Standardization (JWG 0.1.1); In: IAG Reports 2011-2015 (Travaux de líAIG Vol. 39), http://iag.dgfi.tum.de/index.php?id=329. 


\section{Annex B IAG Resolution No. 3, 2019: Establishment of the International Height Reference Frame (IHRF)}

Adopted by the IAG Council at the XXVIIth IUGG General Assembly, Montreal, Canada, July 8-18, 2019

The International Association of Geodesy,

\section{Considering,}

- The IAG Resolution for the Definition and Realization of an International Height Reference System (IHRS) released at the XXVIth IUGG General Assembly in July 2015;

\section{Acknowledging,}

- The achievements of

- GGOS Focus Area "Unified Height System" and its JWG 0.1.2 "Strategy for the Realization of the International Height Reference System (IHRS)",

- IAG JWG 2.2.2 "The $1 \mathrm{~cm}$ geoid experiment",

- IAG SC 2.2 "Methodology for geoid and physical height systems",

- ICCT JSG 0.15 "Regional geoid/quasi-geoid modelling - Theoretical framework for the subcentimetre accuracy";

- in realizing this resolution;

\section{Noting,}

- The need of an operational infrastructure to ensure the determination, maintenance and availability of an International Height Reference Frame (IHRF) in the long-term basis;

\section{Urges,}

- All countries to engage with the IAG and concerned components, in particular the International Gravity Field Service (IGFS), in order to promote and support the implementation of the IHRF by o Installing IHRF reference stations at national level,

- Conducting the necessary gravimetric surveys to guarantee the precise determination of potential values, o Making data available open access,

- Contributing to the development of analysis strategies to improve the estimation of reference coordinates and modelling of the Earth's gravity field,

- Describing, archiving and providing geodetic products associated to the IHRF. 